\title{
Estudi experimental del tir parabòlic
}

\author{
Ernest Arnau Marco (adjunts@gmail.com) IES Quartó de Portmany (St. Antoni, Eivissa)
}

Al llarq del present article explicarem dos mètodes per obtenir les posicions d'una pilota a partir d'una gravació de vídeo: extracció i tractament d'imatqes. A continuació mostrarem una metodoloqia per a realitzar la seva representació gràfica amb el que potenciarem l'ús de les noves tecnologies.

Paraules clau: tir parabòlic, imatges, representació, superposició, equacions del moviment

In this article two methods for obtaining an exact ball position from a video recording will be analysed using a programme for extracting and analysing images. To give relevance to the use of new technological methods, we are going to use and explain a methodology to achieve its graphic representation.

Key words: parabolic shot, pictures, representation, superposition, movement equations

\section{INTRODUCCIÓ}

L'estudi del moviment ha tingut diversos punts de vista al llarg del segles. Així, per a Aristòtil els tirs parabòlics tenien dos fases. Una primera en la qual el cos avançava recte i una segona part en què, al perdre la seva velocitat, tenia un moviment completament vertical. Segons la filosofia Aristotèlica els dos moviments no es podien donar al mateix temps (Oliva, 2004).

Aquesta idea del tir parabòlic en dos fases perdurà centenars d'anys veient-se modificada molt poc. Els primers canvis consistiren en assumir una part en que les dues fases del moviment coincidien. Hem d'esperar fins als estudis de Galileu per consolidar l'actual model del tir parabòlic; fet sorprenent donat la visió que poden oferir els salts d'aigua o la trajectòria d'un doll en una font.

\section{OBJECTIU}

En aquest article mostrarem els procediments pels quals, a partir d'una gravació, poder extraure una sèrie de fotografies, fer-ne una superposició i per últim representar el moviment.

\section{PROCEDIMENT}

Dividirem l'article en dues fases:

- Extraure una seqüència de fotografies d'un vídeo i fer-ne una superposició.

- Utilitzar el programari Logger Pro 3 per a realitzar una gràfica posició-temps del tir parabòlic.

\section{Primera fase: extracció de la se- qüència de fotografies.}

En primer lloc cal fer una gravació d'una pilota en tir parabòlic. Al nostre cas, per facilitar la posterior visualització, hem pintat la pilota d'un color cridaner. L'extracció de la seqüència de fotografies la realitzarem amb el programa multiplataforma Quicktime Pro. Obrim l'arxiu de vídeo amb dit programa per a continuació, si la gravació és del nostre gust,desar la seqüència d'imatges.

arxiu --> Exportar --> Exportar en "Pel-lícula com seqüència d'imatges.

Però abans de guardar picarem a "opcions" on elegirem el format de les imatges de sortida i el nombre de fotogrames per segon. Al nostre cas 30 
per segon; posteriorment farem l'elecció de les fotografies diferents i calcularem el temps transcorregut.

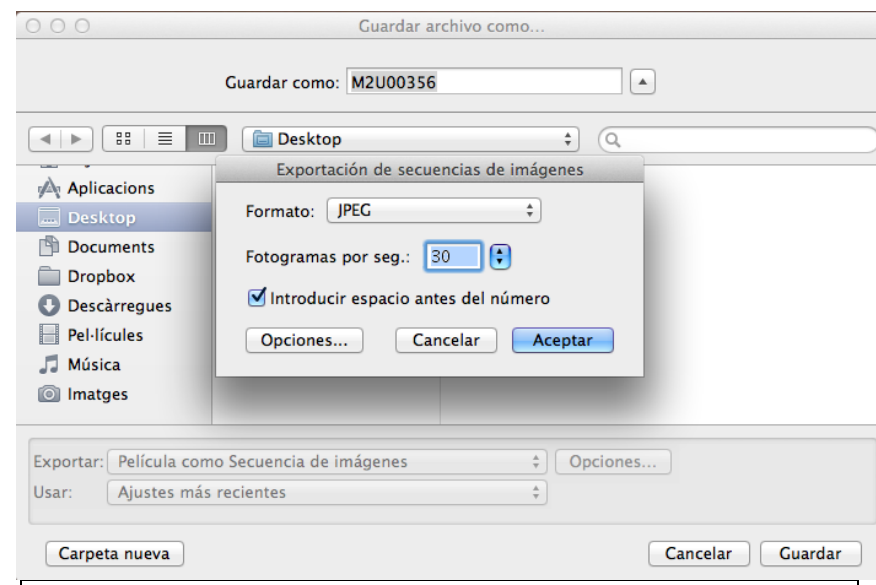

Imatge 1. Captura de pantalla mostrant com desar imatges a partir d'un vídeo.

Amb aquests passos haurem aconseguit una sèrie de fotografies amb les posicions de les pilotes cada 1/30 segons. Realitzarem una superposició de les imatges amb el programari Pixelmator (Imatge 2), on clarament tenim un moviment parabòlic.

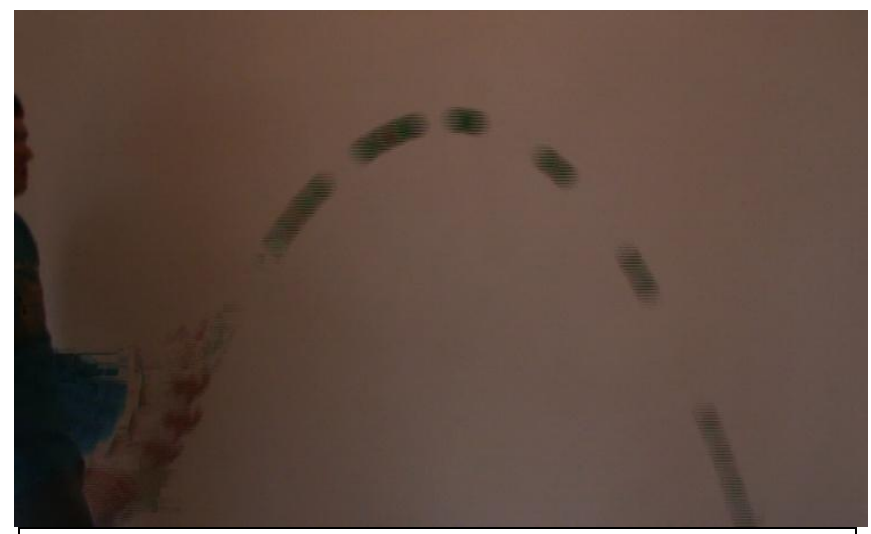

Imatge 2. Superposició de les fotografies del vídeo.

\section{Gràfica posició-temps del tir parabò- lic.}

En aquest cas utilitzarem el programari específic Logger Pro 3 que ens permet extreure valors de posició i velocitat (tant en x com y) d'una gravació.

Per fer-ho obrirem el programa Logger Pro per a continuació incorporar la gravació (Imatge 3).

\section{Insert $\rightarrow$ Movie..}

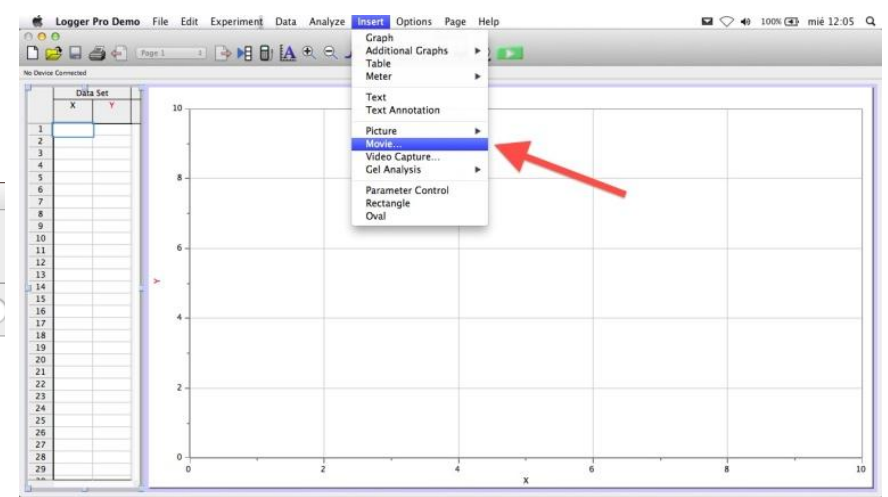

Imatge 3. Presentació del programa Logger Pro 3, es mostra com insertar el vídeo de la gravació.

Tindrem una nova pantalla (imatge 4) on indicarem els punts que corresponen a la pilota. La imatge 4 mostra diferents punts, aquests corresponen a:

- (1) Mostrar el panel lateral.

- (2) i (3) Selecció de les posicions de la pilota, al picar-li quedarà marcada i registrada la posició de la pilota. Automàticament passarà a la següent imatge enregistrada per la gravació, si en eixa no volem fer elecció del punt sols haurem de picar en "॥"

- (4) Permet seleccionar l'origen de coordenades.

- (5) Indicar la distància que agafem com a referència. Per exemple, marquem la llargària del braç i li indiquem que són, al nostre cas, 42 centímetres.

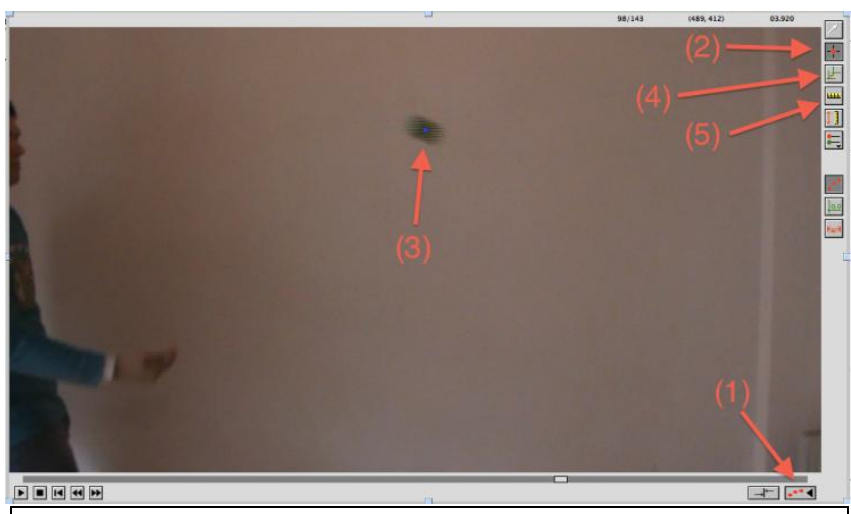

Imatge 4. Passos per seleccionar la posició de la pilota amb el programa Logger Pro 3

Una volta seleccionats tots els punts corresponents al moviment de la pilota tindrem una gràfica amb la trajectòria en $y, x i$ també la velocitat en $x \mathrm{i}$ y. Amb els valors podrem, amb el propi programa Logger Pro o amb l'Excel, ajustar els punts a una equació. 


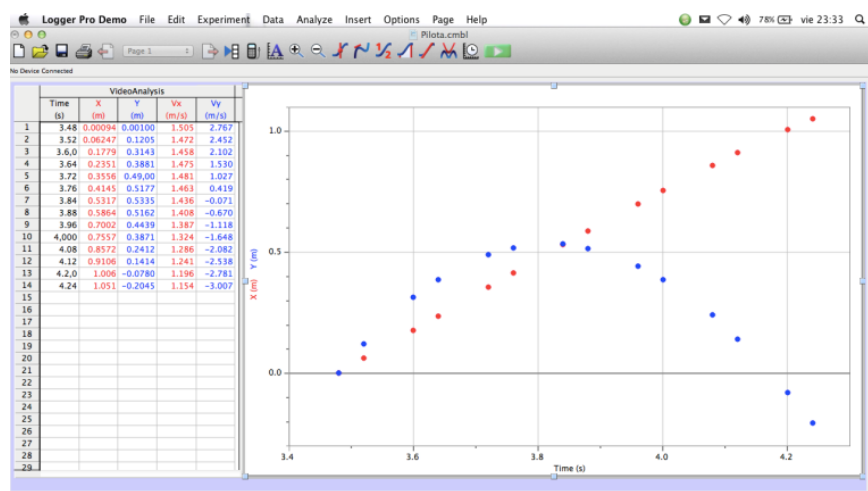

Imatge 5. Valors obtinguts amb Logger Pro després de la selecció de posicions, imatge 4

\section{PROPOSTES DUTILITACIÓ EN L'AULA}

Les possibilitats que ofereix el tractament d'imatges/gravacions en física són múltiples. En aquest punt citarem sols un parell:

Una de les majors dificultats que troben els alumnes en física és imaginar-se el tipus de moviment plantejat. Com ja hem mostrat, la superposició de fotografies extretes directament de la gravació ens mostra el caràcter parabòlic del moviment. Si a més fem un tractament amb el programari Logger Pro obtindrem que el moviment en la direcció $x$ és lineal mostrant que la velocitat(en dit eix) és constant.

En aquest punt estem en disposició d'una fotografia (Imatge 2) que ens mostra clarament el caràcter parabòlic d'un Ilançament en un angle determinat. D'aquesta podrem extreure conclusions amb els alumnes: què passa si variem l'angle? I si la velocitat inicial augmenta? És igual el temps de pujada que de baixada?

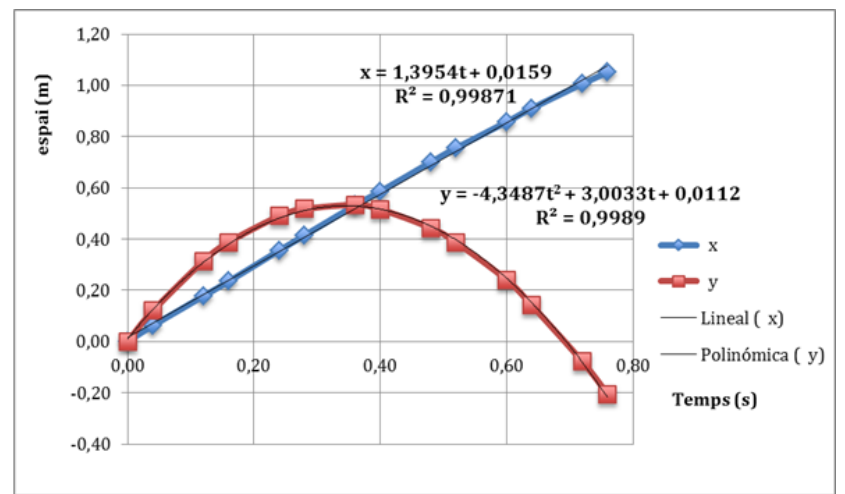

Imatge 6. Representació amb Excel dels valors obtinguts amb Logger Pro, imatge 5
Usualment els llibres de matemàtiques plantegen representacions de taules que els alumnes troben deslligades de la realitat o d'un ús pràctic. $A$ més la societat actual utilitza quotidianament els fulls de càlcul. Amb la representació (Excel) dels valors obtinguts amb Logger Pro solucionem aquests fets: apliquem tot allò après en altres assignatures en un cas pràctic i utilitzem el programari Excel (o la versió lliure Openoffice)

De la representació (Imatge 6):

- $\mathrm{x}=1,3954 \mathrm{t}+0,0159$ d'on podem observar que és un M.R.U $\left(x=v_{0} \cdot t+x_{0}\right)$.

- $y=-4,348 \mathrm{t}^{2}+3,003 \mathrm{t}+0,011$ que ens mostra el M.R.U.A $\left(y=\frac{1}{2} a \cdot t^{2}+v_{0 y} \cdot t+y_{0}\right)$.

\section{BIBLIOGRAFIA}

OLIVA MARTÍNEZ, J. M. i ACEVEDO DÍAZ, J., (2004), Pensamiento analógico y movimiento de proyectiles. Revista Española de ciencia. Octubre-Diciembre 2004 